\title{
The dermatophyte species Arthroderma benhamiae: intraspecies variability and mating behaviour
}

\section{Correspondence \\ Michel Monod \\ Michel.Monod@chuv.ch}

Received 1 October 2012

Accepted 15 November 2012

\section{Françoise Symoens, ${ }^{1}$ Olivier Jousson, ${ }^{2}$ Ann Packeu, ${ }^{1}$ Marina Fratti, ${ }^{3}$ Peter Staib, ${ }^{4}$ Bernard Mignon ${ }^{5}$ and Michel Monod ${ }^{3}$}

\author{
${ }^{1}$ Mycology \& Aerobiology Section, Scientific Institute of Public Health, Brussels, Belgium \\ ${ }^{2}$ Centre for Integrative Biology (CIBIO), University of Trento, Italy \\ ${ }^{3}$ Department of Dermatology, Centre Hospitalier Universitaire Vaudois, Lausanne, Switzerland \\ ${ }^{4}$ Junior Research Group Fundamental Molecular Biology of Pathogenic Fungi, Leibniz Institute for \\ Natural Product Research and Infection Biology - Hans Knoell Institute, Jena, Germany \\ ${ }^{5}$ Department of Infectious and Parasitic Diseases, Parasitology, Faculty of Veterinary Medicine, \\ University of Liège, Liège, Belgium
}

\begin{abstract}
Arthroderma benhamiae is a zoophilic dermatophyte belonging to the Trichophyton mentagrophytes species complex. Here, a population of $A$. benhamiae wild strains from the same geographical area (Switzerland) was studied by comparing their morphology, assessing their molecular variability using internal transcribed spacer (ITS) and 28S rRNA gene sequencing, and evaluating their interfertility. Sequencing of the ITS region and of part of the 28S rRNA gene revealed the existence of two infraspecific groups with markedly different colony phenotypes: white (group I) and yellow (group II), respectively. For all strains, the results of mating type identification by PCR, using HMG (high-mobility group) and $\alpha$-box genes in the mating type locus as targets, were in total accordance with the results of mating type identification by strain confrontation experiments. White-phenotype strains were of mating type $+(\mathrm{mt}+)$ or mating type $(\mathrm{mt}-)$, whilst yellow-phenotype strains were all $\mathrm{mt}-$. White and yellow strains were found to produce fertile cleistothecia after mating with $A$. benhamiae reference tester strains, which belonged to a third group intermediate between groups I and II. However, no interfertility was observed between yellow strains and white strains of $\mathrm{mt}+$. A significant result was that white strains of $\mathrm{mt}-$ were able to mate and produce fertile cleistothecia with the white $A$. benhamiae strain CBS $112371(\mathrm{mt}+)$, the genome of which has recently been sequenced and annotated. This finding should offer new tools for investigating the biology and genetics of dermatophytes using wild-type strains.
\end{abstract}

\section{INTRODUCTION}

Arthroderma benhamiae is a zoophilic dermatophyte species belonging to the Trichophyton mentagrophytes complex, which produces highly inflammatory tinea corporis and tinea capitis on humans. The natural reservoir of this species is guinea pigs (Fumeaux et al., 2004; Drouot et al., 2009). A. benhamiae isolates are generally recognized by the production of numerous pyriform or round microconidia, a characteristic of species of the T. mentagrophytes complex, and by considering the probable source of the infection,

Abbreviations: HMG, high-mobility group; ITS, internal transcribed spacer; $\mathrm{mt}+$, mating type + ; $\mathrm{mt}-$, mating type - .

The GenBank/EMBL/DDBJ accession number for the sequence of the A. benhamiae strain IHEM $3288 \alpha$-domain-encoding gene determined in this study is JX656700. which is generally a guinea pig. They can be identified further by DNA sequence analysis of a $318 \mathrm{bp}$ fragment of the 28S rRNA gene and/or of the internal transcribed spacer (ITS) region (Ninet et al., 2003; Fumeaux et al., 2004). Like other dermatophyte species, A. benhamiae is heterothallic and is able to produce cleistothecia (sexual fructifications) containing asci and ascospores when strains from two different mating types, mating type $+(\mathrm{mt}+)$ and mating type - (mt-), meet. A. benhamiae was selected as an appropriate species for fundamental research on dermatophytes for several practical reasons: (i) the species grows relatively fast in comparison with other dermatophyte species; (ii) it produces abundant microconidia, which are useful for genetic manipulation (Grumbt et al., 2011); and (iii) A. benhamiae causes inflammatory cutaneous infections in guinea pigs, allowing the establishment of an animal 
infection model (Staib et al., 2010). The genome of an A. benhamiae strain (LAU 2354=IHEM 20161=CBS 112371), isolated from a patient with highly inflammatory tinea faciei, has recently been sequenced and annotated (Burmester $e t$ al., 2011). This strain was found to be suitable for targeted gene deletion and in vivo analysis of putative virulence gene function in A. benhamiae (Grumbt et al., 2011).

During the last few years, a constantly increasing number of A. benhamiae strains has been isolated in the Department of Dermatology (Centre Hospitalier Universitaire Vaudois, Lausanne, Switzerland) from guinea pigs, and from patients suffering from highly inflammatory mycoses who have guinea pigs as pets. We compared their morphology, assessed their molecular variability by ITS and $28 \mathrm{~S}$ rRNA gene sequencing and evaluated their interfertility. A major objective of the present investigation was the isolation of wild-type strains able to produce fertile cleistothecia with the sequenced strain to facilitate further genetic analyses and determine the mechanisms of sexual development in dermatophytes. Our investigations revealed the existence of two infraspecific groups with markedly different colony phenotypes. In one group, both mating types were found, whilst strains of the second group were all $\mathrm{mt}-$.

\section{METHODS}

Fungal isolates and tester strains. A. benhamiae strains were isolated by seeding human and animal hair and scrapings on two culture media: Sabouraud agar medium with chloramphenicol $\left(50 \mu \mathrm{g} \mathrm{ml}^{-1}\right)$ (Bio-Rad) and Sabouraud agar medium with chloramphenicol (50 $\mu \mathrm{g}$ $\mathrm{ml}^{-1}$ ) plus cycloheximide $\left(400 \mu \mathrm{g} \mathrm{ml}^{-1}\right)$ (BD). The cultures were incubated at $30{ }^{\circ} \mathrm{C}$. Dermatophytes were observed macroscopically and microscopically after 14-21 days. Presumptive identification of A. benhamiae was based on white colonies with the production of numerous pyriform microconidia or on downy yellow mycelium with poor sporulation. DNA sequence analysis of the ITS was performed to make this identification. Twenty-seven wild-type strains, all originating from Switzerland, were used for mating experiments. They were referenced and preserved in the BCCM/IHEM Collection (Scientific Institute of Public Health, Brussels, Belgium, http://bccm.belspo.be/db/ ihem_search_form.php). These strains were isolated from dermatological lesions in human patients $(n=20)$, guinea pigs $(n=6)$ or dog $(n=1)$. Most human patients had had previous contact with guinea pigs.

Four A. benhamiae single-ascospore strains were used as reference strains. Two were from the Vanbreuseghem Collection (RV Collection, nowadays integrated into the BCCM/IHEM Collection) and were used as tester strains: IHEM 3287=RV 26678 [=SA-3 from Takashio (1974), RV $23302 \times \mathrm{RV} 23303] \mathrm{mt}+$, and IHEM 3288=RV 26680 [=SA-5 from Takashio (1974); RV $23302 \times \mathrm{RV} 23303] \mathrm{mt}-$. Two other strains from the CBS Collection were the type strains of $A$. benhamiae: CBS $623.66=$ type strain of $\mathrm{mt}+[\mathrm{TM} 20 \times \mathrm{TM} 17=\mathrm{ATCC}$ 16781; Ajello \& Cheng (1967)] and CBS 624.66=type strain of $\mathrm{mt}-$ [TM20 $\times$ TM17=ATCC 16782; Ajello \& Cheng (1967)].

All yellow isolates were poorly sporulating on Sabouraud agar. They were subcultured on potato dextrose agar (PDA) medium (BD) and on M40Y medium [2\% (w/v) Difco Bacto malt extract, $4 \%$ (w/v) sucrose, $2 \%(\mathrm{w} / \mathrm{v})$ Difco Bacto yeast extract] to enhance their sporulating ability.

DNA extraction. DNA was extracted from fresh dermatophyte cultures on Sabouraud agar medium. Approximately $1 \mathrm{~cm}^{2}$ mycelium was collected and transferred into an Eppendorf tube containing $1 \mathrm{ml}$ distilled water, and fungal DNA was extracted using a DNeasy plant mini kit (Qiagen) according to the manufacturer's protocol. The DNA was eluted from the disposable spin column with $50 \mu$ distilled water, and $1 \mu \mathrm{l}$ of this DNA suspension was used for PCR.

PCR and sequencing. Extracted DNA $(1 \mu \mathrm{l}), 2.5 \mu \mathrm{l}$ each sense and antisense oligonucleotide $(42 \mathrm{mM}$; Table 1$), 4 \mu \mathrm{l}$ dNTP mix (containing $10 \mathrm{mM}$ each $\mathrm{dNTP}$ ) and $5 \mu \mathrm{l} 10 \times$ concentrated PCR buffer [100 mM Tris/ $\mathrm{HCl}$ (pH 8.3), $500 \mathrm{mM} \mathrm{KCl}$ and $15 \mathrm{mM} \mathrm{MgCl}$ ] were mixed with deionized water up to a total reaction volume of $50 \mu \mathrm{l}$. To each reaction, $2.5 \mathrm{U}$ AmpliTaq DNA polymerase (Perkin Elmer) was added. The reaction mixture was incubated for $1 \mathrm{~min}$ at $94{ }^{\circ} \mathrm{C}$, subjected to 40 cycles of $30 \mathrm{~s}$ at $94{ }^{\circ} \mathrm{C}, 30 \mathrm{~s}$ at $55^{\circ} \mathrm{C}$ and $30 \mathrm{~s}$ at $72{ }^{\circ} \mathrm{C}$, and finally incubated for $10 \mathrm{~min}$ at $72{ }^{\circ} \mathrm{C}$ for a final extension.

DNA sequencing was performed by Microsynth on an FLX genome sequencer (454 sequencing; Roche). All sequences were compared with sequences available in GenBank using the BLASTN algorithm at National Center for Biotechnology Information.

Mating experiments (confrontations). The medium for mating experiments was prepared according to the method of De Vroey (1964) and consisted of $3 \%(\mathrm{w} / \mathrm{v})$ ground seeds of Guizotia abyssinica (from a seed store) and $2 \%(\mathrm{w} / \mathrm{v})$ agar in distilled water in agar plates

Table 1. Primers used in this study

\begin{tabular}{|c|c|c|c|c|c|}
\hline Use & $\begin{array}{l}\text { Fragment } \\
\text { amplified }\end{array}$ & $\begin{array}{c}\text { Primer } \\
\text { name }\end{array}$ & Primer sequence $\left(5^{\prime} \rightarrow 3^{\prime}\right)$ & $\begin{array}{l}\text { Amplicon } \\
\text { (bp) }\end{array}$ & References \\
\hline \multirow[t]{2}{*}{ Identification } & \multirow[t]{2}{*}{ ITS } & ITS1 & GGTTGGTTTCTTTTCCT & \multirow[t]{2}{*}{650} & \multirow[t]{2}{*}{ Ninet et al. (2003) } \\
\hline & & ITS2 & AAGTAAAAGTCGTAACAAGG & & \\
\hline \multirow[t]{2}{*}{ Identification $28 \mathrm{~S}$ rRNA type } & \multirow[t]{2}{*}{$28 \mathrm{~S}$} & LSU1 & GATAGCGMACAAGTAGAGTG & \multirow[t]{2}{*}{$317-319$} & \multirow[t]{2}{*}{ Ninet et al. (2003) } \\
\hline & & LSU2 & GTCCGTGTTTCAAGACGGG & & \\
\hline \multirow[t]{2}{*}{ Screening for $\mathrm{mt}-$} & \multirow[t]{2}{*}{ HMG partial } & MF1 & ATGGCCACTACTTCTGGGACC & \multirow[t]{2}{*}{307} & Kano et al. (2012) \\
\hline & & MF2 & CATTGGTAAAACAGCAGCCCC & & This study \\
\hline \multirow[t]{2}{*}{ Screening for $\mathrm{mt}+$} & \multirow[t]{2}{*}{$\alpha$-Box partial } & MF3 & AAAATGTCTGGCACCGAAGTCTC & \multirow[t]{2}{*}{380} & Kano et al. (2012) \\
\hline & & MF4 & TCTGGGAGAGATCGGGAAACGC & & This study \\
\hline \multirow[t]{2}{*}{ HMG gene sequence } & \multirow[t]{2}{*}{ HMG } & MF1 & ATGGCCACTACTTCTGGGACC & \multirow[t]{2}{*}{1234} & Kano et al. (2012) \\
\hline & & MF5 & TCATCAAGGAAGTATTTCGTCG & & This study \\
\hline \multirow[t]{2}{*}{$\alpha$-Box gene sequence } & \multirow[t]{2}{*}{$\alpha$-Box } & MF3 & AAAATGTCTGGCACCGAAGTCTC & \multirow[t]{2}{*}{1207} & Kano et al. (2012) \\
\hline & & MF6 & TCACATGTCAACGTAGTCATTAA & & This study \\
\hline
\end{tabular}


$9 \mathrm{~cm}$ in diameter. For each confrontation test, two strains were inoculated at $3 \mathrm{~cm}$ distance from each other in the centre of a Petri dish. After incubation for $4-6$ weeks at $25{ }^{\circ} \mathrm{C}$ in the dark, the cultures were observed for the presence or absence of cleistothecia or pseudocleistothecia using a binocular microscope. Microscopic examinations of the squashed cleistothecia or pseudocleistothecia were performed to visualize the presence or absence of asci and ascospores, respectively. The mating type assigned to each wild strain was the opposite of the mating type of the reference tester strain when cleistothecia or pseudocleistothecia were formed.

\section{RESULTS}

Over a 10 year period (2002-2012), dermatophytes isolated from tinea corporis and tinea capitis in humans and isolated from animals were routinely identified in our laboratory on the basis of macroscopic and microscopic characteristics of the cultures, as well as by DNA sequence analysis. Twenty-seven isolates from humans $(n=20$, most of them known to have had contact with guinea pigs), from guinea pigs $(n=6)$ and from a $\operatorname{dog}(n=1)$ were identified as A. benhamiae and retained for further analyses. The phenotype, sequences [ITS, 28S rRNA gene, high-mobility group (HMG) and $\alpha$-box] and mating with singleascospore tester strains and wild-type strains are detailed for all strains in Table 2.

\section{Morphology}

Isolated strains could be classified into two groups according to their growth phenotype on agar plates: white (group I) or yellow (group II). The growth rate of strains from group I was faster than that of strains from group II (Fig. 1a, b). White-phenotype strains $(n=14)$ formed colonies with various colour and surface textures, a reverse of the colony from brown to chamois and, in general, the production of numerous pyriform microconidia on Sabouraud agar medium. The mycelium was downy for some strains (IHEM 22723, 22725, 25075, 25080, 25078, 25059 and 25061), some of which showed sectors with pleomorphism (IHEM 22723, 25078 and 25080) or a powdery aspect (IHEM 25076, 20161, 25064, 25062, 22710, 25063 and 25071) (Fig. 1a). The white-phenotype strains had a morphology resembling the isolates of Trichophyton interdigitale and Arthroderma vanbreuseghemii usually isolated from tinea pedis and other tinea, respectively.

The yellow-phenotype strains $(n=13)$ formed homogeneous colonies characterized by a yellow-to-orange velvety mycelium and few irregular folds (Fig. 1b). No or only a few microconidia were observed on Sabouraud agar medium; however, sporulation was observed on PDA and M40Y media (data not shown).

The reference strains of $A$. benhamiae CBS 623.66 and CBS 624.66 [single ascospore from Ajello \& Cheng (1967)], as well as IHEM 3287 and 3288 [single-ascospore tester strains from Takashio (1974)], showed a typically white phenotype (powdery, with numerous microconidia).

\section{S rRNA gene and ITS sequencing}

All 14 A. benhamiae strains of group I had a 28S rRNA gene sequence identical to GenBank accession no. GU646875 (deposited for strain IHEM 3287). All 13 strains of group II (yellow phenotype) had a $28 \mathrm{~S}$ rRNA gene sequence identical to GenBank accession no. GU646876 (deposited for strain IHEM 22710). These two sequences differed by mutations at positions 173 and 261. In a recent molecular analysis of the T. mentagrophytes complex, these DNA sequences were called type V and type VI with reference to types I-III, which are characteristic of A. vanbreuseghemii and T. interdigitale, two other species of the T. mentagrophytes complex (Ninet et al., 2003; Symoens et al., 2011). Type IV corresponded to the neotype of T. mentagrophytes (Gräser et al., 1999), recently described as corresponding to Trichophyton quinckeanum (Beguin et al., 2012).

Two ITS sequences differing by a nucleotide substitution were found in A. benhamiae strains of group I. Twelve strains had an ITS sequence identical to GenBank accession no. AY315661 (deposited for strain LAU 2352), whilst two strains (IHEM 25063 and 25071) had an ITS sequence identical to GenBank accession no. AB048192, as reported for a strain isolated in Japan, KMU4136 (Kawasaki et al., 2002). All strains of group II had an ITS sequence identical to GenBank accession no. AB088677, as well as to the type $A$. benhamiae strains CBS 623.66 and CBS 624.66 and the mating tester strains IHEM 3287 and 3288 (Takashio, 1974). Sequence AB088677 differed by 7 and 8 nt substitutions in comparison with AY315661 and AB048192, respectively.

\section{Screening for mating type by PCR and mating type gene sequencing}

The A. benhamiae genes encoding, respectively, $\mathrm{mt}-(\alpha-$ box transcription factor) and $\mathrm{mt}+$ (HMG transcription factor) proteins have been sequenced recently by Kano et al. (2012). Based on these sequences, two oligonucleotide primer pairs (MF1/MF2 and MF3/MF4; Table 1) were designed to identify the mating type of $A$. benhamiae strains by PCR. As expected, the $\mathrm{mt}+$ strain IHEM 3287 and CBS623.66 (type strain) were PCR positive for the $H M G$ gene and negative for the $\alpha$-box gene, respectively. Conversely, the mt- strains IHEM 3287 and CBS624.66 (type strain) were PCR negative for the HMG gene and positive for the $\alpha$-box gene.

All white-phenotype strains of group I with an ITS sequence identical to AY315661 were PCR positive for an $H M G$ gene. The sequence of the amplicon (1224 bp) was $100 \%$ identical to region 348380-349603 of the genomic sequence of GenBank accession no. XM_003014173. This region encodes the mating type protein MAT1-2-1 (locus_tag='ARB_07320', ARB locus tags being related to the A. benhamiae genome sequence via http://www.broadinstitute.org/annotation/geno me/dermatophyte_comparative/MultiHome.html). The two white-phenotype strains IHEM 25063 and IHEM 25071, with an ITS sequence identical to GenBank accession no. 
Table 2. Details of the strains used in this work: ITS, 28S rRNA gene, HMG factor and $\alpha$-factor sequences, and confrontation results

(a) Tester strains (monoascospore) and new tester strains.

\begin{tabular}{|c|c|c|c|c|c|c|c|}
\hline Acronym/no. & Origin & $\begin{array}{l}\text { Mating } \\
\text { type }\end{array}$ & ITS sequence & $28 S$ sequence $^{\star}$ & HMG factor sequence & $\begin{array}{l}\alpha \text {-Factor } \\
\text { sequence }\end{array}$ & $\begin{array}{l}\text { Confrontation results } \\
\text { with tester strain }\end{array}$ \\
\hline IHEM $3287=$ RV 26678 & M & $\mathrm{mt}+$ & AB088677 & GU646875 & AB570253 & & \\
\hline IHEM $3288=$ RV 26680 & M & $\mathrm{mt}-$ & AB088677 & GU646875 & & JX656700 & \\
\hline CBS623.66 (type strain) & $\mathrm{M}$ & $\mathrm{mt}+$ & AB088677 & GU646875 & AB570253 & & \\
\hline CBS624.66 (type strain) & M & $\mathrm{mt}-$ & AB088677 & GU646875 & & JX656700 & \\
\hline IHEM 25063 & $\mathrm{H}$ & $\mathrm{mt}-$ & AB048192 & GU646876 & & GQ996965† & CAA with 3287 \\
\hline IHEM 25071 & $\mathrm{H}$ & $\mathrm{mt}-$ & AB048192 & GU646876 & & GQ996965† & CAA with 3287 \\
\hline IHEM 25075 & $\mathrm{H}$ & $\mathrm{mt}+$ & AY315661 & GU646876 & XM_003014713 & & CAA with 3288 \\
\hline IHEM 20161=CBS 112371§ & $\mathrm{H}$ & $\mathrm{mt}+$ & AY315661 & GU646876 & XM_003014713 & & CAA with 3288 \\
\hline
\end{tabular}

(b) Strains of group I (white phenotype).

\begin{tabular}{|c|c|c|c|c|c|c|c|c|c|}
\hline \multirow[t]{2}{*}{ Acronym/no. } & \multirow[t]{2}{*}{ Origin } & \multirow{2}{*}{$\begin{array}{l}\text { Mating } \\
\text { type }\end{array}$} & \multirow[t]{2}{*}{ ITS sequence } & \multirow[t]{2}{*}{$28 S$ sequence $^{*}$} & \multirow{2}{*}{$\begin{array}{l}\text { HMG factor } \\
\text { sequence }\end{array}$} & \multirow[t]{2}{*}{$\alpha$-Factor sequence } & \multicolumn{3}{|c|}{ Confrontation results with: } \\
\hline & & & & & & & $\begin{array}{c}\text { Tester strain IHEM } \\
3287 \text { or } 3288^{\| \prime}\end{array}$ & $\begin{array}{c}\text { IHEM } 25063 \\
\text { type VI }\end{array}$ & $\begin{array}{c}\text { IHEM } 25071 \\
\text { type VI }\end{array}$ \\
\hline IHEM 25063 & $\mathrm{H}$ & $\mathrm{mt}-$ & AB048192 & GU646876 & & GQ996965† & CAA & ND & $\varnothing$ \\
\hline IHEM 25071 & $\mathrm{H}$ & $\mathrm{mt}-$ & AB048192 & GU646876 & & GQ996965† & CAA & $\varnothing$ & $\mathrm{ND}$ \\
\hline IHEM 25075 & $\mathrm{H}$ & $\mathrm{mt}+$ & AY315661 & GU646876 & XM_003014713末 & & CAA & CAA & CAA \\
\hline IHEM 20161=CBS $112371 \S$ & $\mathrm{H}$ & $\mathrm{mt}+$ & AY315661 & GU646876 & XM_003014713‡ & & CAA & CAA & CAA \\
\hline IHEM 25076 & $\mathrm{H}$ & $\mathrm{mt}+$ & AY315661 & GU646876 & XM_003014713‡ & & CAA & CAA & CAA \\
\hline IHEM 25080 & GP & $\mathrm{mt}+$ & AY315661 & GU646876 & XM_003014713 & & CAA & CAA & CAA \\
\hline IHEM 25078 & GP & $\mathrm{mt}+$ & AY315661 & GU646876 & XM_003014713 & & CAA & CAA & CAA \\
\hline IHEM 25064 & $\mathrm{H}$ & $\mathrm{mt}+$ & AY315661 & GU646876 & XM_003014713‡ & & CAA & $\varnothing$ & CAA \\
\hline IHEM 25059 & $\mathrm{H}$ & $\mathrm{mt}+$ & AY315661 & GU646876 & XM_003014713 & & Pseudo & $\varnothing$ & Pseudo \\
\hline IHEM 25061 & $\mathrm{H}$ & $\mathrm{mt}+$ & AY315661 & GU646876 & XM_003014713末 & & Pseudo & $\varnothing$ & CAA \\
\hline IHEM 25062 & $\mathrm{H}$ & $\mathrm{mt}+$ & AY315661 & GU646876 & XM_003014713末 & & CAA & $\varnothing$ & CAA \\
\hline IHEM 22710 & GP & $\mathrm{mt}+$ & AY315661 & GU646876 & XM_003014713‡ & & CAA & CAA & CAA \\
\hline IHEM 22723 & GP & $\mathrm{mt}+$ & AY315661 & GU646876 & XM_003014713‡ & & CAA & CAA & CAA \\
\hline IHEM 22725 & GP & $\mathrm{mt}+$ & AY315661 & GU646876 & XM_003014713末 & & CAA & CAA & CAA \\
\hline
\end{tabular}


(c) Strains of group II (yellow phenotype).

\begin{tabular}{|c|c|c|c|c|c|c|c|c|c|}
\hline \multirow[t]{2}{*}{ Acronym/no. } & \multirow[t]{2}{*}{ Origin } & \multirow{2}{*}{$\begin{array}{l}\text { Mating } \\
\text { type }\end{array}$} & \multirow[t]{2}{*}{ ITS sequence } & \multirow[t]{2}{*}{$28 \mathrm{~S}$ sequence* } & \multirow{2}{*}{$\begin{array}{c}\text { HMG factor } \\
\text { sequence }\end{array}$} & \multirow[t]{2}{*}{$\alpha$-Factor sequence } & \multicolumn{3}{|c|}{ Confrontation results with: } \\
\hline & & & & & & & $\begin{array}{l}\text { Tester strain } \\
\text { IHEM } 3287\end{array}$ & $\begin{array}{c}\text { IHEM } 25075 \\
\text { type VI }\end{array}$ & $\begin{array}{c}\text { IHEM 20161末 } \\
\text { type VI }\end{array}$ \\
\hline IHEM 23024 & $\mathrm{H}$ & $\mathrm{mt}-$ & AB088677 & GU646875 & & JX656700 & CAA & $\varnothing$ & $\varnothing$ \\
\hline IHEM 22718 & GP & $\mathrm{mt}-$ & AB088677 & GU646875 & & JX656700 & CAA & $\varnothing$ & $\varnothing$ \\
\hline IHEM 25065 & $\mathrm{H}$ & $\mathrm{mt}-$ & AB088677 & GU646875 & & JX656700 & Pseudo & $\varnothing$ & $\varnothing$ \\
\hline IHEM 25066 & $\mathrm{H}$ & $\mathrm{mt}-$ & AB088677 & GU646875 & & JX656700 & CAA & $\varnothing$ & $\varnothing$ \\
\hline IHEM 25067 & $\mathrm{H}$ & $\mathrm{mt}-$ & AB088677 & GU646875 & & JX656700 & Pseudo & $\varnothing$ & $\varnothing$ \\
\hline IHEM 25068 & $\mathrm{H}$ & $\mathrm{mt}-$ & AB088677 & GU646875 & & JX656700 & Pseudo & $\varnothing$ & $\varnothing$ \\
\hline IHEM 25069 & $\mathrm{H}$ & $\mathrm{mt}-$ & AB088677 & GU646875 & & JX656700 & Pseudo & $\varnothing$ & $\varnothing$ \\
\hline IHEM 25070 & $\mathrm{H}$ & $\mathrm{mt}-$ & AB088677 & GU646875 & & JX656700 & $\mathrm{CAA}$ & $\varnothing$ & $\varnothing$ \\
\hline IHEM 25072 & $\mathrm{H}$ & $\mathrm{mt}-$ & AB088677 & GU646875 & & JX656700 & Pseudo & $\varnothing$ & $\varnothing$ \\
\hline IHEM 25073 & $\mathrm{H}$ & $\mathrm{mt}-$ & AB088677 & GU646875 & & JX656700 & CAA & $\varnothing$ & $\varnothing$ \\
\hline IHEM 25074 & $\mathrm{H}$ & $\mathrm{mt}-$ & AB088677 & GU646875 & & JX656700 & Pseudo & $\varnothing$ & $\varnothing$ \\
\hline IHEM 25079 & Dog & $\mathrm{mt}-$ & AB088677 & GU646875 & & JX656700 & Pseudo & $\varnothing$ & $\varnothing$ \\
\hline IHEM 25077 & $\mathrm{H}$ & $\mathrm{mt}-$ & AB088677 & GU646875 & & JX656700 & CAA & $\varnothing$ & $\varnothing$ \\
\hline
\end{tabular}

$\emptyset$, No pseudocleistothecia or cleistothecia; CAA, cleistothecia, asci and ascospores; GP, guinea pig; H, human; M, monoascospore; ND, not done; pseudo, pseudocleistothecia.

${ }^{*} \mathrm{GU} 646875$ sequence is type V; GU646876 sequence is type VI.

†GQ996965 $\alpha$-factor sequence nt 10578-11781.

‡XM_003014713 HMG factor sequence nt 10578-11781.

\$IHEM 20161 was the reference strain for sequencing.

IIMating with tester strain IHEM 3287 for three $\mathrm{mt}-$ strains and with IHEM 3288 for $\mathrm{mt}+$ strains 


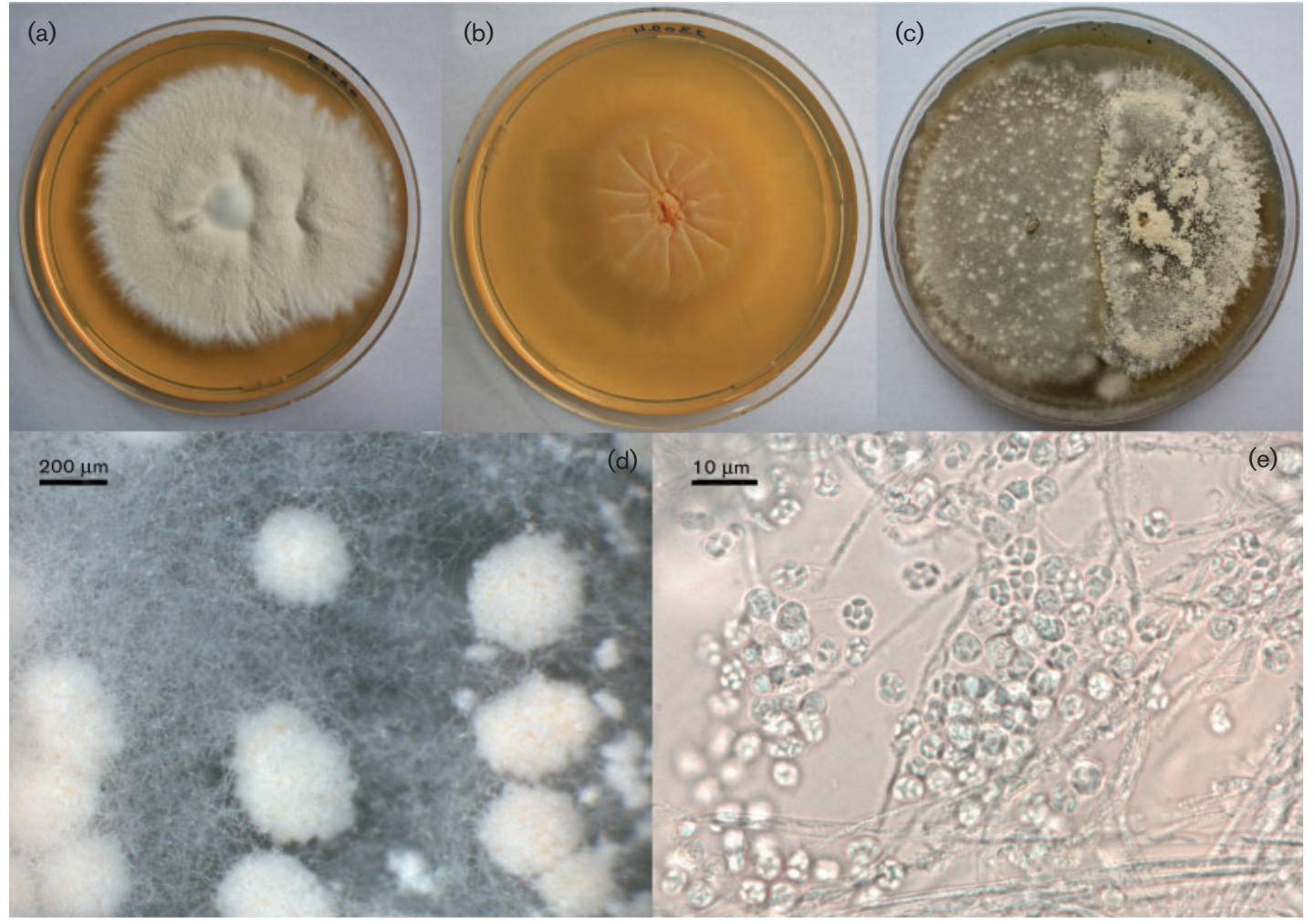

Fig. 1. (a) A. benhamiae IHEM 20161=CBS 112371 (group I) characterized by a white phenotype on Sabouraud agar medium. (b) A. benhamiae IHEM 23024 (group II) characterized by a yellow phenotype. (c) Mating of $A$. benhamiae IHEM 20161 (mt +) with IHEM 25071 (mt-), showing a line of cleistothecia. (d) Cleistothecia. (e) Squashed cleistothecium showing asci and ascospores.

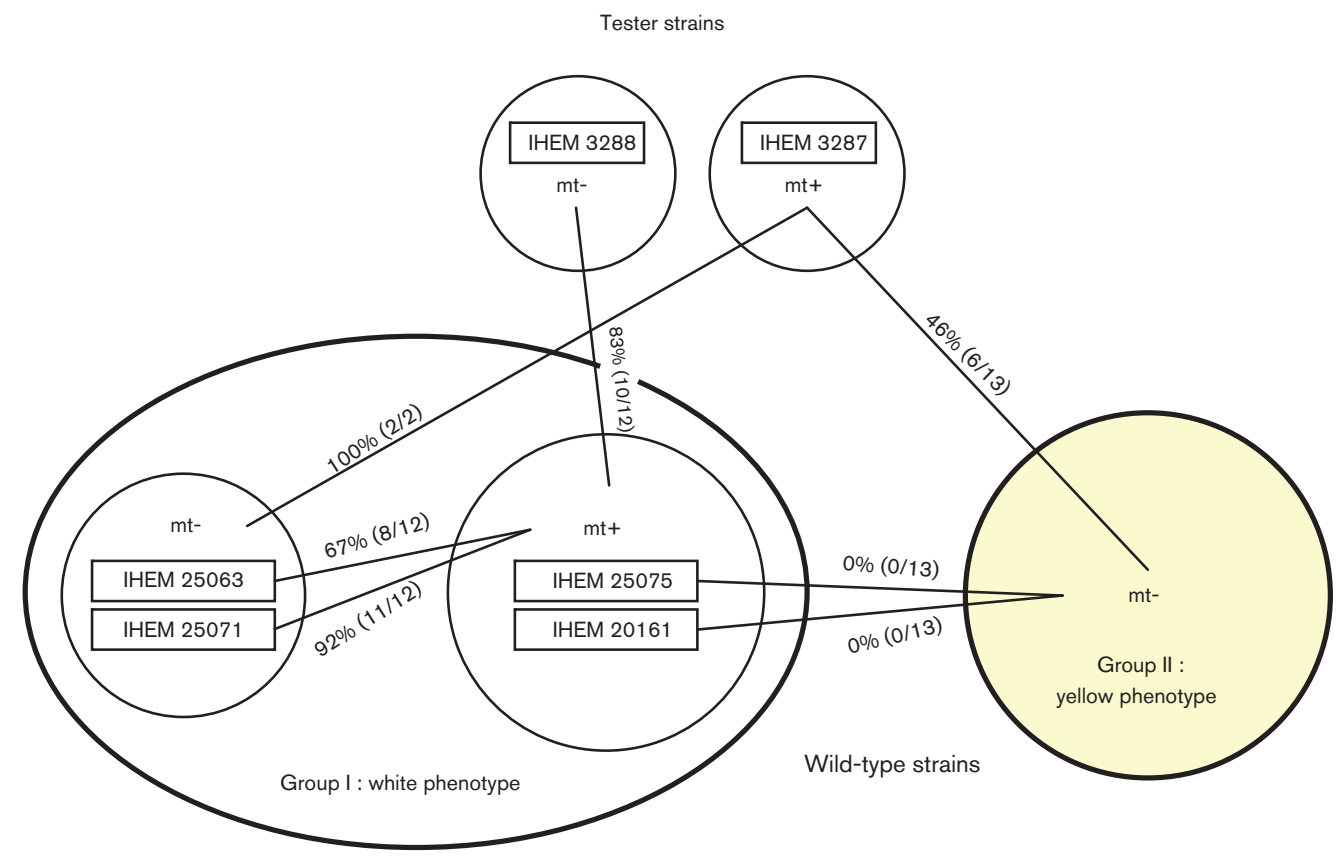

Fig. 2. Interfertility ratios between A. benhamiae tester strains and wild-type strains of group I (white phenotype) and group II (yellow phenotype). 
$\mathrm{AB} 048192$, and all strains of group II were PCR positive for an $\alpha$-box gene. The sequence of the amplicon (1204 bp) obtained for IHEM 25063 and IHEM 25071 was $100 \%$ identical to part of the sequence of GenBank accession no. GQ996965 (nt 10578-11781), which encodes the mating type protein MAT1-1-1 ( $\alpha$-box transcription factor). The sequence of the amplicon (1204 bp) obtained for yellow-phenotype strains was $100 \%$ identical to that obtained for the tester strain IHEM 3288 and the type strain CBS 624.66 (GenBank accession no. JX656700) but differed by four substitutions from the sequences obtained for strains IHEM 25063 and IHEM 25071.

\section{Interfertility of $\boldsymbol{A}$. benhamiae isolated strains}

Interfertility in ascomycete fungi depends on various genes that are expressed under the control of both transcription HMG and $\alpha$ factors. The detection of both mating types by PCR in a strain population does not provide information about strain interfertility. The ability of isolated wild-type strains to mate and produce fertile cleistothecia was examined independently of their mating type identification by PCR. Mating experimental results for each strain are presented in Table 2 and summarized in Fig. 2.

Fertile cleistothecia (containing asci and ascospores) were obtained by mating experiments based on the tester strain IHEM $3288(\mathrm{mt}-)$, with 10 out of 12 strains of group I containing an HMG box, whilst only pseudocleitothecia were obtained with the 2 other strains. Fertile cleistothecia were produced in mating experiments for each of the two strains of group I, IHEM 25063 and 25071, containing an $\alpha$-box in the tester strain IHEM $3287(\mathrm{mt}+)$. Six of the thirteen strains of group II that contained an $\alpha$-box produced fertile cleistothecia with the tester strain IHEM 3287. The seven other strains produced pseudocleistothecia. In conclusion, using monoascospore tester strains IHEM 3287 and 3288, more fertile confrontations were produced with strains from group I than with strains of group II (86 vs $46 \%)$.

In a second round of confrontations, the 12 wild-type strains of group I that had an HMG box $(\mathrm{mt}+)$ were mated with the two strains IHEM 25063 and 25071 of the same group, but with an $\alpha$-box $(\mathrm{mt}-)$. Fertile cleistothecia were obtained in confrontations between 8 strains $(66 \%)$ with IHEM 25063 and in confrontations of 11 strains (92\%) with IHEM 25071 (Fig. 1c-e). All 13 yellow strains of group II of $\mathrm{mt}-$ were also mated with two group I wildtype strains of $\mathrm{mt}+$ (IHEM 25075 and 20161) that were selected for their fertility based on the single-ascospore tester strains. No fertile cleistothecia or pseudocleistothecia were obtained in any of these confrontations. A barrier of stimulation containing a fragment of peridium was observed at the site of confrontation (meeting of the strains). However, for all strains, results of mating type identification by strain confrontations were in total accordance with the results of PCR detection of specific mating HMG and $\alpha$-box genes.

\section{DISCUSSION}

DNA sequencing and mating experiments revealed that $A$. benhamiae strains with a white phenotype (group I) and those with a yellow phenotype (group II) belonged to two infraspecific groups. Phylogenetic analyses of ITS sequences confirmed this statement, with the sequences of isolates from both groups forming monophyletic clades differing by 7 nt substitutions (1.3\% divergence) (Fig. 3 ). Both groups were phylogenetically closely related and formed a sister group to Trichophyton verrucosum and Trichophyton erinacei. It can be seen that the A. benhamiae group II clade also included Trichophyton concentricum, a rare anthropophilic species from the South Pacific area causing the uncommon superficial mycosis tinea imbricata (Pihet et al., 2008). Strains of both groups were found to mate and produce fertile cleistothecia with $A$. benhamiae tester strains. However, no interfertility was observed between wild-type strains of group II, all $\mathrm{mt}-$, and selected strains of group I with $\mathrm{mt}+$. A. benhamiae tester strains isolated by Takashio (1972) (RV 26678 and RV 26680) were monoascospore strains generated from mating experiments with strain RV $23302(\mathrm{mt}+)$ and RV23303 ( $\mathrm{mt}-$ ). Because of the loss of their ability to form abundant cleistothecia, RV23302 and RV23303 were not used as tester strains. No data are available on the origin and the carriers of these two strains, but our results showed that they were intermediate between the strains of white and yellow phenotypes characterized in the present study, as they presented the white phenotype and a $28 \mathrm{~S}$ rRNA gene sequence of type $\mathrm{V}$ like all strains with a yellow phenotype.

BLASTN searches revealed that strains with an ITS sequence $100 \%$ identical to that found in the white-phenotype strains of group I with mt + (GenBank accession no. AY315661) were isolated in Finland from a human and from rabbits (IFM 41154, IFM 41156, IFM 41176, IFM 41200 and IFM 41187). Many strains with an ITS sequence $100 \%$ identical to that found in the white-phenotype strains of group I with mt- (GenBank accession no. AB048192) were isolated in Japan from humans and rabbits (Kawasaki et al., 2002; data in GenBank but unpublished), and in France from guinea pigs, rabbits, one chinchilla and a dog (Fréalle et al., 2007).

During the preparation of this manuscript, yellowphenotype strains of group II with a sequence identical to GenBank accession no. AB088677 have been isolated in Belgium from guinea pigs and cats (B. Mignon and M. Monod, unpublished data). Yellow-phenotype strains of group II have also been described in France as a new variety under the name T. mentagrophytes var. porcellae (ContetAudonneau \& Leyer, 2010). An ITS sequence of these strains was not provided. This new variety has not been described and deposited according to the formal requirements, and we therefore suggest that the name Arthroderma benhamiae is retained and that the phenotype of the culture (white or yellow) is noted. According to the rules proposed by the Amsterdam declaration on Fungal Nomenclature (one fungus=one name; Hawksworth et al., 2011), the sexual 


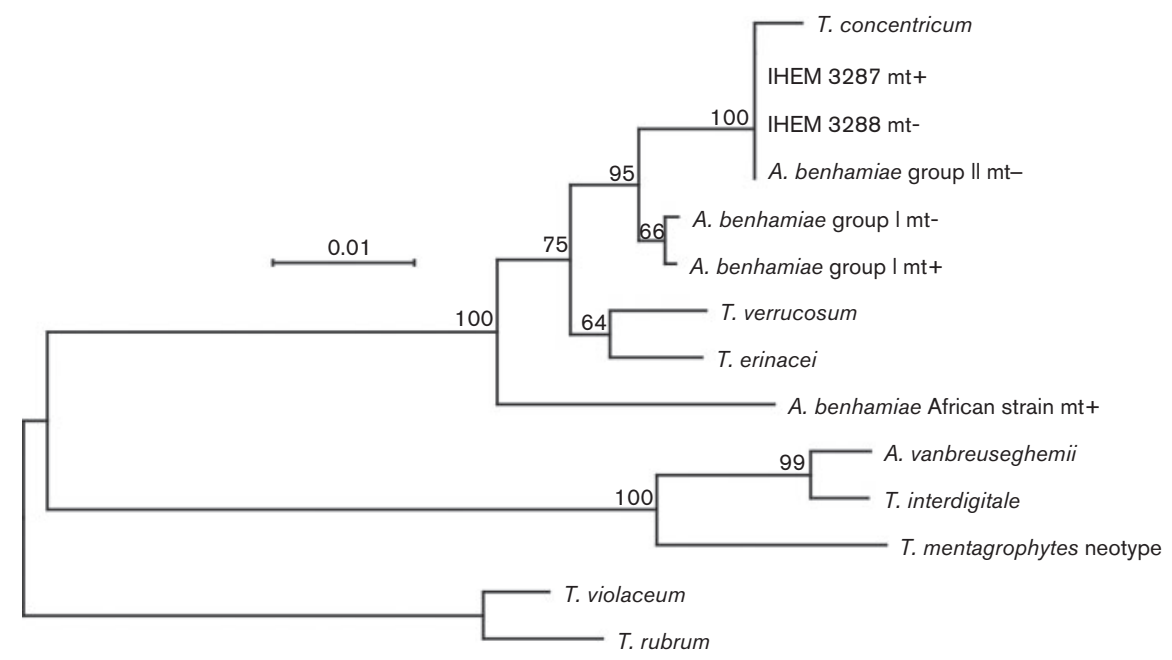

Fig. 3. Phylogenetic tree from complete Arthroderma and Trichophyton aligned ITS sequences of 735 sites, based on the FastME algorithm (Desper \& Gascuel, 2002). The final tree resulted from evaluating candidate trees generated by extensive nearest-neighbour interchange. The numbers at nodes represent bootstrap values (500 replicates). T. rubrum and Trichophyton violaceum ITS sequences were used as a potential outgroup. Bar, number of substitutions per site. GenBank accession numbers are: AB088677 for $A$. benhamiae group II mt-, IHEM $3287 \mathrm{mt}+$, IHEM3288 mt-; EU083910 for T. concentricum; AB048192 for $A$. benhamiae group I mt- ; AY315661 for $A$. benhamiae group I mt +; Z98002 for T. verrucosum; EU622882 for $T$. erinacei; AF170456 for $A$. benhamiae African strain mt+; AF506034 for A. vanbreuseghemii; EU181446 for $T$. interdigitale; Z97995 for T. mentagrophytes neotype; EU590656 for T. violaceum; AF170472 for T. rubrum.

name A. benhamiae should always be used. However, the asexual name T. mentagrophytes is still in use in routine clinical laboratories for white-phenotype strains, morphologically similar to A. vanbreuseghemi, when identifications are based only on morphological criteria, and when data about the origin of the strains are not available.

All yellow-phenotype strains reported in France were isolated from patients with inflammatory dermatophytoses, having had previous contact with guinea pig (ContetAudonneau \& Leyer, 2010). In our study, 12 of the 14 yellow-phenotype strains were of human origin, and most of the patients were also in contact with guinea pigs. These strains can also be transmitted by animal species other than guinea pigs, as one strain was isolated from a dog.

The proportion of the two mating types in our sample of wild-type strains (groups I and II) could suggest a rather homogeneous distribution of $\mathrm{mt}+$ and $\mathrm{mt}-$ strains (12 $\mathrm{mt}+/ 15 \mathrm{mt}-)$ in A. benhamiae. However, this is not the case when each group is considered separately. Both mating types were isolated within group I of $A$. benhamiae strains, but only two $\mathrm{mt}-$ strains were detected by PCR, a powerful method for screening a large population of isolates in order to tentatively detect strains of both mating types in a given species. In A. benhamiae strains of group II, only one mating type was detected, similar to the anthropophilic or zoophilic species Trichophyton rubrum, T. interdigitale and Trichophyton equinum, in which sexual reproduction has never been observed (Stockdale, 1968). A bias towards one particular mating type was observed for other dermatophyte species. Most strains of A. vanbreuseghemii are $\mathrm{mt}+$ (Hironaga \& Watanabe, 1980; ContetAudonneau \& Percebois, 1981; Symoens et al., 2011). In contrast, most strains of Nannizzia otae (the teleomorph of Microsporum canis) are mt- (Sharma et al., 2007). The high fertility rate obtained using $A$. benhamiae isolates with a white phenotype suggests that genetic exchanges could occur in nature. An unequal prevalence of the two opposite mating types has also been observed in other pathogenic fungal species such as Cryptococcus neoformans (Idnurm et al., 2005), Cryptococcus gattii (Fraser et al., 2005) and Histoplasma capsulatum (Kwon-Chung et al., 1974). The prevalence of one mating type may be due to differences in their pathogenicity (Rippon \& Garber, 1969). For A. benhamiae, our results did not support such an hypothesis.

The A. benhamiae strain CBS 112371 (LAU 2354=IHEM 20161), whose genome was recently sequenced and annotated, belonged to group I in the present study. This strain was used further to investigate the biology of dermatophytes by targeted gene inactivation (Grumbt et al., 2011). Until now, the generation of dermatophytes with several mutations has remained a challenge, as only two dominant resistance selection markers, $h p h$ (hygromycin) and neo (neomycin), are currently available. Under these conditions, the ability of wild-type strains from the same group (group I) to mate and produce fertile cleistothecia with the CBS 112371 strain is an interesting tool, allowing the breeding of a single ascospore with multiple mutations. This result could further facilitate genetic analyses and help 
elucidate the mechanism of sexual development in dermatophytes using A. benhamiae as a model.

\section{REFERENCES}

Ajello, L. \& Cheng, S. L. (1967). The perfect state of Trichophyton mentagrophytes. Sabouraudia 5, 230-234.

Beguin, H., Pyck, N., Hendrickx, M., Planard, C., Stubbe, D. \& Detandt, M. (2012). The taxonomic status of Trichophyton quinckeanum and $T$. interdigitale revisited: a multigene phylogenetic approach. Med Mycol 50, 871-882.

Burmester, A., Shelest, E., Glöckner, G., Heddergott, C., Schindler, S., Staib, P., Heidel, A., Felder, M., Petzold, A. \& other authors (2011). Comparative and functional genomics provide insights into the pathogenicity of dermatophytic fungi. Genome Biol 12, R7.

Contet-Audonneau, N. \& Leyer, C. (2010). Emergence d'un dermatophyte transmis par le cochon d'Inde et proche de Trichophyton mentagrophytes var. erinacei: T. mentagrophytes var. porcellae. J Mycol Med 20, 321-325.

Contet-Audonneau, N. \& Percebois, G. (1981). Mating types of strains of the "mentagrophytes complex" in relation to clinical lesions. In Sexuality and Pathogenicity of Fungi, pp. 160-163. Edited by R. Vanbreuseghem \& C. De Vroey. Paris, New York: Masson.

De Vroey, C. (1964). Formes sexuées des dermatophytes. production de cleistothèces de Microsporum gypseum (Bodin) Guiart et Grigorakis sur divers milieux stériles. Ann Soc Belg Med Trop 44, 831-840.

Desper, R. \& Gascuel, O. (2002). Fast and accurate phylogeny reconstruction algorithms based on the minimum-evolution principle. J Comput Biol 9, 687-705.

Drouot, S., Mignon, B., Fratti, M., Roosje, P. \& Monod, M. (2009). Pets as the main source of two zoonotic species of the Trichophyton mentagrophytes complex in Switzerland, Arthroderma vanbreuseghemii and Arthroderma benhamiae. Vet Dermatol 20, 13-18.

Fraser, J. A., Giles, S. S., Wenink, E. C., Geunes-Boyer, S. G., Wright, J. R., Diezmann, S., Allen, A., Stajich, J. E., Dietrich, F. S. \& other authors (2005). Same-sex mating and the origin of the Vancouver Island Cryptococcus gattii outbreak. Nature 437, 1360-1364.

Fréalle, E., Rodrigue, M., Gantois, N., Aliouat, C. M., Delaporte, E., Camus, D., Dei-Cas, E., Kauffmann-Lacroix, C., Guillot, J. \& Delhaes, L. (2007). Phylogenetic analysis of Trichophyton mentagrophytes human and animal isolates based on MnSOD and ITS sequence comparison. Microbiology 153, 3466-3477.

Fumeaux, J., Mock, M., Ninet, B., Jan, I., Bontems, O., Léchenne, B., Lew, D., Panizzon, R. G., Jousson, O. \& Monod, M. (2004). First report of Arthroderma benhamiae in Switzerland. Dermatology 208, 244-250.

Gräser, Y., Kuijpers, A. F., Presber, W. \& De Hoog, G. S. (1999). Molecular taxonomy of Trichophyton mentagrophytes and T. tonsurans. Med Mycol 37, 315-330.

Grumbt, M., Defaweux, V., Mignon, B., Monod, M., Burmester, A., Wöstemeyer, J. \& Staib, P. (2011). Targeted gene deletion and in vivo analysis of putative virulence gene function in the pathogenic dermatophyte Arthroderma benhamiae. Eukaryot Cell 10, 842853.

Hawksworth, D. L., Crous, P. W., Redhead, S. A., Reynolds, D. R., Samson, R. A., Seifert, K. A., Taylor, J. W., Wingfield, M. J., Abaci, O. \& other authors (2011). The Amsterdam declaration on fungal nomenclature. IMA Fungus 2, 105-112.

Hironaga, M. \& Watanabe, S. (1980). Mating behaviour of 334 Japanese isolates of Trichophyton mentagrophytes in relation to their ecological status. Mycologia 72, 1159-1170.

Idnurm, A., Bahn, Y. S., Nielsen, K., Lin, X., Fraser, J. A. \& Heitman, J. (2005). Deciphering the model pathogenic fungus Cryptococcus neoformans. Nat Rev Microbiol 3, 753-764.

Kano, R., Kawasaki, M., Mochizuki, T., Hiruma, M. \& Hasegawa, A. (2012). Mating genes of the Trichophyton mentagrophytes complex. Mycopathologia 173, 103-112.

Kawasaki, M., Inoue, T., Ohsawa, T., Ishioka, S., Mochizuki, T. \& Ishizaki, H. (2002). Two Arthroderma benhamiae isolates showing mitochondrial DNA type of Trichophyton verrucosum. Nippon Ishinkin Gakkai Zasshi 43, 103-106.

Kwon-Chung, K. J., Weeks, R. J. \& Larsh, H. W. (1974). Studies on Emmonsiella capsulata (Histoplasma capsulatum). II. Distribution of the two mating types in 13 endemic states of the United States. Am J Epidemiol 99, 44-49.

Ninet, B., Jan, I., Bontems, O., Léchenne, B., Jousson, O., Panizzon, R., Lew, D. \& Monod, M. (2003). Identification of dermatophyte species by $28 \mathrm{~S}$ ribosomal DNA sequencing with a commercial kit. J Clin Microbiol 41, 826-830.

Pihet, M., Bourgeois, H., Mazière, J. Y., Berlioz-Arthaud, A., Bouchara, J. P. \& Chabasse, D. (2008). Isolation of Trichophyton concentricum from chronic cutaneous lesions in patients from the Solomon Islands. Trans R Soc Trop Med Hyg 102, 389-393.

Rippon, J. W. \& Garber, E. D. (1969). Dermatophyte pathogenicity as a function of mating type and associated enzymes. J Invest Dermatol 53, 445-448.

Sharma, R., De Hoog, S., Presber, W. \& Gräser, Y. (2007). A virulent genotype of Microsporum canis is responsible for the majority of human infections. J Med Microbiol 56, 1377-1385.

Staib, P., Zaugg, C., Mignon, B., Weber, J., Grumbt, M., Pradervand, S., Harshman, K. \& Monod, M. (2010). Differential gene expression in the pathogenic dermatophyte Arthroderma benhamiae in vitro versus during infection. Microbiology 156, 884-895.

Stockdale, P. M. (1968). Sexual stimulation between Arthroderma simii Stockd., Mackenzie \& Austwick and related species. Sabouraudia 6, 176-181.

Symoens, F., Jousson, O., Planard, C., Fratti, M., Staib, P., Mignon, B. \& Monod, M. (2011). Molecular analysis and mating behaviour of the Trichophyton mentagrophytes species complex. Int J Med Microbiol 301, 260-266.

Takashio, M. (1972). Is Arthroderma benhamiae the perfect state of Trichophyton mentagrophytes? Sabouraudia 10, 122-127.

Takashio, M. (1974). Observations on African and European strains of Arthroderma benhamiae. Int J Dermatol 13, 94-101. 